be given on Monday, beginning at noon.

Five tutorial sessions by leading experts will be held on Sunday. Concentrating on new, rapidly breaking areas of research these sessions will cover $\mathrm{GaN}$ Electronic and Photonic Devices; Ferroelectric Thin Films; New Trends in Applications of Plasma Processing of Polymers; Synthesis of Inorganic Materials; and Materials in Space: Science, Technology, and Exploration.

Symposium X, Frontiers of Materials Research, will present authoritative reviews for nonspecialists during noontime sessions Tuesday through Thursday. In addition to the Turnbull lecture on Wednesday, other presentations will cover materials science in the automotive industry, silicon micromechanics, perspectives from the U.S. Office of Science and Technology Policy's division of sci- ence, and industrial partnering at Lawrence Livermore National Laboratory.

A major exhibit encompassing the full spectrum of equipment, instrumentation, products, software, publications, and services will be held Tuesday through Thursday in the Boston Marriott and Westin Hotels, with a reception on Tuesday evening from 5:00-6:30 p.m. in University Hall, Boston Marriott.

The meeting also includes major poster sessions Monday through Wednesday in all three hotels along with Best Poster Competitions featuring awards to the presenting authors of the most outstanding posters as selected by the Meeting Chairs. Posters will be judged on their technical content, overall appearance, graphic excellence, and presentation quality.

A Student Mixer is planned Sunday evening for graduate students and mem- bers of MRS University Chapters. Also, University Chapter officers and faculty advisors are invited to attend a meeting of MRS University Chapter representatives to compare notes on recent activities and brainstorm on new projects and issues of common concern.

For job seekers a Job Center will be conducted 9:00 a.m.-5:00 p.m. Tuesday through Thursday and a Career Workshop is scheduled for Wednesday.

The 1998 Fall Meeting program is available on the MRS Website: www.mrs. org/meetings/Fall98. For additional copies of the program to share with colleagues, call MRS: 724-779-3003, or e-mail: info@mrs.org. The deadline to preregister for the meeting is Friday, November 13. See the following pages for a matrix of symposia sessions, profiles of exhibitors, and other information.

\title{
Plenary Speaker Richard E. Smalley to Discuss Commercially Available Buckytubes
}

Distinguished recipient of the 1996 Nobel Prize in Chemistry Richard E. Smalley of Rice University will deliver the plenary talk at the 1998 Materials Research Society Fall Meeting in Boston on November 30, at 6:00 p.m. in Salon E of the Boston Marriott. In his talk entitled, "Buckytubes: New Materials and New Devices from Carbon," Smalley will address the tubular extensions of fullerenes now available commercially in small quantities. According to Smalley, in short lengths buckytubes are expected to be the most rigid of beams and effectively unbreakable even when bent in half. He said, "Grown in long ropes they are expected to form the strongest fiber made, with a tensile strength approximately 100 times stronger than steel at only one-sixth the weight." Buckytubes have potential applications in molecular electronics.

Since joining Rice University in 1976, Smalley has risen rapidly through the academic ranks. He was one of the founders of the Rice Quantum Institute in 1979 , and served as chair of this interdisciplinary institute from 1986 to 1996 . In 1982 he was named to the Gene and Norman Hackerman Chair in Chemistry. Since January 1990 he has also been a Professor in the Department of Physics. He was appointed Director of the new

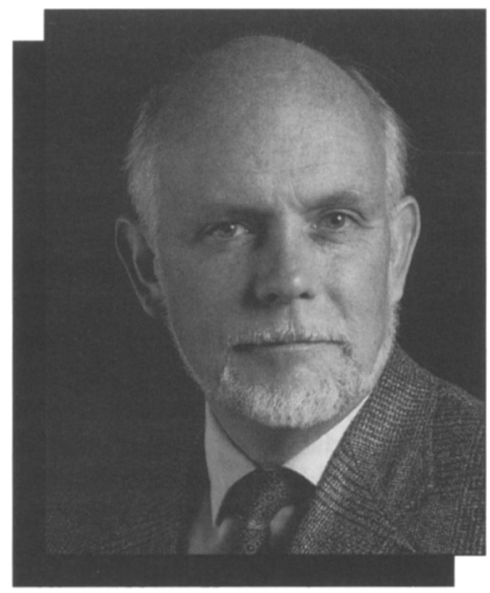

Richard E. Smalley

Center for Nanoscale Science and Technology at Rice in 1996.

Smalley has made pioneering advances in the development of experimental techniques-including supercold pulsed beams; the ultrasensitive laser detection technique; laser-driven production of free radicals, triplets, metals, and both metal and semiconductor cluster beams-and has applied these techniques to a broad range of vital questions in chemical physics. He is widely known for the dis- covery and characterization of $\mathrm{C}_{60}$ (buckminsterfullerene) which, together with other fullerenes such as $C_{70}$, now constitutes the third elemental form of carbon (after graphite and diamond). His group was the first to generate fullerenes with metals trapped on the inside.

Smalley received his BS degree in 1965 from the University of Michigan and his PhD degree from Princeton University in 1973, with an intervening four-year period as a research chemist with Shell Chemical Co. During an unusually productive postdoctoral period with Lennard Wharton and Donald Levy at the University of Chicago, Smalley pioneered supersonic beam laser spectroscopy, which has become one of the most powerful techniques in chemical physics.

In 1990 Smalley was elected to the National Academy of Sciences, and in 1991 to the American Academy of Arts and Sciences. He is the recipient of several prizes, including the 1991 Irving Langmuir Prize in Chemical Physics from the American Physical Society; the 1992 APS International Prize for New Materials, which he shares with his colleagues R.F. Curl and H.W. Kroto; the 1997 American Carbon Society Medal; and the 1997 Distinguished Public Service Award from the Department of the Navy. 